\title{
The Impact of Intelligent Society on Human Essence and the New Evolution of Humans ${ }^{+}$
}

\author{
Kun Wu and Kaiyan Da * \\ School of Humanities and Social Sciences, Xi'an Jiaotong University, Xi'an 710049, China; \\ wukun@mail.xjtu.edu.cn \\ * Correspondence: dky850731@stu.xjtu.edu.cn; Tel.: +86-1896-690-3388 \\ + The Fourth International Conference on Philosophy of Information, Berkeley, CA, USA, 2-6 June 2019. \\ Published: 15 May 2020
}

\begin{abstract}
When we enter intelligent society, we need to rethink about the topic of human essence. As we know, human beings have no absolute, fixed essence. The essence of human beings is the combination of an innate substrate and acquired creation. As the degree of machine intelligence in the development of human society continues to increase, human beings are constantly changing and creating their own essence, and they are also constantly liberated from the bondage of a certain single old essence, creating and enriching the richer and more diverse aspects of its essence. The transformation of labor from its alienation to its return is also a transformation of labor from the centralized form to the non-centralized form of human essence according to Karl Marx. The new fusion of artificial intelligence and bioengineering will lead to a new track of evolution that "reshapes and regenerates" life itself. This new evolutionary path will fuse the two-track evolution, biological evolution and cultural evolution, which have been relatively isolated in the traditional sense. If human beings are able to work hard together to design and implement a new social system that adapts to the future intelligent development, then the comprehensive development of intelligence that human beings bring about would be not a disaster, but a bright future.
\end{abstract}

Keywords: intelligence; human essence; new evolution of human beings; social system

\section{Introduction}

As we enter the 21st century, the development of the information society of human beings has entered a new stage of intelligent development. A scenario that we can imagine is that a large number of traditional industries have been or will be replaced by robots and machine systems. The rapid growth of unemployed people will also become an inevitable trend of the development of human society. To explain this trend, people have begun to put forward various future reveries, which also cause deep panic and anxiety. However, we believe that as the degree of machine intelligence in social development increases, the shortening of the necessary labor time for human beings will be an irreversibly inevitable trend, and the resulting rapid growth of the number of unemployed people is the concentrated expression of social progress. Correspondingly, the traditional relevant theories and doctrines putting production labor as the concentrated embodiment of the essence of human beings should also be rethought. So, this paper is going to talk about a series of problems such as the human essence, the ways and characteristics of the formation of human essence, and the new evolution of humans [1].

\section{Characteristics of Human Essence}

Humans have their own unique essence, which is totally different from animals. Animals have their essence when they are born, but the essence of humans cannot be completely determined at 
birth, and they create their own essence in the multi-dimensional interaction factors in the acquired environment. These corresponding dimensions include the natural, the social, the physiological, the psychological, and the behavioral. An obvious fact is that children raised by wild animals do not have the essence of humans. They generally behave in the same way as their adoptive parents. The concrete essential aspects of those who grow up in different social environments also vary [2]. The essence of humans is open. Landmann said that "Human beings are more inherently indeterminate than animals. This means that the life of human beings does not follow a pre-determined route. In fact, nature only makes human beings walk over a half way, and the other half is still to be done by the human beings themselves." [3].

From the process of the development of human history, from the individual characteristics of humans and the construction of the way of existence, we can conclude that humans have no absolute and fixed essence. The essence of humans is the combination of nature and society, history and reality, innate substrate and acquired creation, and is the unity of determinism and indeterminism, certainty and uncertainty.

\section{Characteristics of Labor as the Real Essence of Humans}

Labor, as a concentrated form of the real essence of human beings, is also a concrete and historical phenomenon. This historical concreteness of labor should include two aspects: First, at different stages of human history, labor has its own concrete forms of existence that are consistent with that particular historical stage; second, the historical concreteness of labor will eventually lead to a trend in which, with the continuous improvement of social productivity, at a certain stage of human development, labor will also change its dominant position in human activity. The form of activities that carries the real essence of human beings will no longer be labor, but other activities of human beings.

The historical concreteness of labor makes our understanding of the essence of human beings a transition from abstract labor to vivid and concrete labor. It is based on the special understanding of labor that we have seen the rich diversity, historical concreteness and overall structure of human essence.

Dialectics regards the inherent contradiction of things as the basis for the development of things. Labor, as the main form of human activity, still has its own inherent contradictions. The aspect of this internal contradiction is nothing else but the structure of labor itself. It is the contradictory movement of the unity and conflict of opposites of the inner structure of labor itself that constitutes the history of the evolution of labor itself, which fully embodies the historical, concrete existence and development of human essence.

Although the conditions for return to labor itself were gradually developed in the development process of industrial civilization, the real realization of these conditions depended on another new transition of human civilization, which was the arrival of the era of civilization with information, automation and intelligence. It was the information and intelligence development that had greatly enhanced the ability of human beings to create material and spiritual wealth. Furthermore, one future scenario of its development that had been seen in the reality was the general adoption of intelligent systems and intelligent robots, and their ability to replace and even surpass human beings' physical and mental labor in some aspects, in terms of large degree and scale, which made human beings a new species to achieve their own purposes through their own created intelligent machines.

\section{A New Way of Human Evolution}

Cultural anthropologists have proposed the different ways of evolution between general organisms and human beings a long time ago, which are about the theories of "two-track evolution" and "in vitro evolution" in human society. "Two-track evolution" refers to biological evolution and cultural evolution. The former is the evolution of genetic genes, which is the evolution within the body; the latter is the evolution of cultural traditions and patterns, which is in vitro evolution.

However, a new trend in the development of science and technology of human beings proposes a more revolutionary way of human evolution. That is the new life evolutionary approach of 
"reshaping and regenerating" life body itself caused by the new fusion of artificial intelligence and bioengineering [4]. Canadian biologist Charlies Lumsden and American biologist Edward Wilson once emphasized in their co-authored book Genes, Mind, and Culture: The Co-evolutionary Process that "many philosophers and scientists still consider the gap between the biological and social sciences to be a permanent discontinuity... We view it (human evolution) instead as a largely unknown evolutionary process, a complicated, fascinating interaction, in which culture is generated and shaped by biological imperatives while biological traits are simultaneously altered by genetic evolution in response to cultural innovation..." [5]. Michael Dannemann, postdoctoral research associate at the Max Planck Institute for Evolutionary Anthropology in Leipzig, Germany, and Fernando Racimo, assistant professor of the Department of Integrative Biology of University of California, Berkeley, also think that human evolution is a process of admixture and adaptation, part of which comes from the inheritance of ancient genetic material, or comes by learning from other similar kinds and adapting to the environment. So we can say that in human evolution, something is old and something is borrowed [6]. From this, we can see that this new evolution way will lead to a fusion together of "two-track evolution" in the traditional sense, so that the original, relatively isolated two evolutionary tracks will be fused together to a certain extent, thus by means of cultural evolution directly acting on changes of the genotypes, and thus altering the pattern of genetic evolution.

We are not prophets, but we can start from the current and predictable trends in science and technology of human beings and call for humans to make rational choices about the future. In order to avoid disasters, for the sake of humanity's well-being, human beings should rationally choose the way humans evolve themselves, adopt reasonable policies and measures, and establish a reasonable social system. This is the cause of human beings, as a whole, which should transcend the interests of classes, countries, nations and regions.

\section{Conclusions}

Based on the discussion in this thesis, we can make the following conclusions:

First, human beings have no absolute, fixed essence. The essence of humans is the combination of an innate substrate and acquired creation, which is the unity of determinism and indeterminism, certainty and uncertainty.

Second, the labor that centrally embodies the essence of human beings is historical, concrete and developmental. Human's labor was initially dominated with the production of material goods, and then it gradually separated, generated and intensified some new forms of labor: spiritual production, optimization of human's own production, human relationships' production and virtual production.

Third, with the improvement of mechanization and intelligence, the concentration of labor in the essence of human beings will also be reduced day by day, and the essence of other aspects of human beings may become increasingly prominent such as autonomic learning, conscious research, free creation, games, entertainment, tourism, leisure, etc. This is not only the development and display of the comprehensive essence of human beings, but also the inevitable trend that the liberation of human beings should achieve.

Fourth, the combination of future artificial intelligence and human augmented bioengineering technology will highlight a new way of human development. This new way of development has brought uncertain anticipation to the development prospects of human beings. One extreme result will lead to the differentiation of human beings and the differentiation of human essence. How to avoid negative effects, and the research, discussion, design, and establishment of new economic, political, and social systems will be the key to leading the future.

Fifth, for all kinds of discussions about robotic slavery to human beings, we hold the view that there is only human oppressing human, human using machines to oppress human, and there is no machine directly oppressing human.

Sixth, in the face of future development, the primary task of human beings is how to establish a reasonable social system avoiding war and stopping infighting, as well as establishing a shared 
economy and shared society, letting human beings truly enter a completely new era by creating the future freely and consciously [7].

Funding: This research was funded by National Social Science Fund, grant number 18ZDA027.

Conflicts of Interest: The authors declare no conflict of interest.

\section{References}

1. Wu, K.; Feng, J.; Yuan, Y.; Ma, H.Y. The Institutional Appeal of Intelligent Society and the New Evolution of Human essence. Dialect. Essence 2019, 35, 123-128.

2. $\quad \mathrm{Wu}, \mathrm{K}$. On the Multidimensional Existence of Humans. Qiushi J. 1995, 5, 18-22.

3. Landmann, M. Philosophische Anthropolohie; Li, F., Translator; Workers Press: Beijing, China, 1988; p. 8.

4. Harari, Y.N. 21 Lessons for the 21st Century; Lin, J., Trans.; CITIC Publishing Group: Beijing, China, 2018; pp. 6, 251, 377-385.

5. Charles, J.L.; Edward, O.W. Genes, Mind, and Culture: The Coevolutionary Process; World Scientific Publishing Co. Inc.: Singapore, 2005; p. 352.

6. Dannemann, M.; Racimo, F. Something old, something borrowed: Admixture and adaptation in human evolution. Curr. Opin. Genet. Dev. 2018, 53, 1-8.

7. Wu, K.; Da, K.Y. The Comprehensive Human Essence and the New Evolution of Human Beings. Academics 2019, 8, 185-194.

(C) 2020 by the authors. Licensee MDPI, Basel, Switzerland. This article is an open access article distributed under the terms and conditions of the Creative Commons Attribution (CC BY) license (http://creativecommons.org/licenses/by/4.0/). 